\title{
Evidence for divergent selection and spatial differentiation in a putative zona pellucida gene is indicative of local adaptation in Pacific cod
}

\author{
Ingrid Spies ${ }^{1}$, Daniel Drinan ${ }^{2}$, Eleni Petrou ${ }^{2}$, Rory Spurr ${ }^{2}$, Theodore Hartinger ${ }^{3}$, Carolyn \\ Tarpey $^{2}$, and Lorenz Hauser ${ }^{2}$
}

${ }^{1}$ NOAA Fisheries

${ }^{2}$ University of Washington

${ }^{3}$ Washington Department of Fish and Wildlife

April 13, 2021

\begin{abstract}
Genetic differentiation has been observed in marine species even when no obvious barriers to gene flow exist. The study of highly differentiated outlier loci can provide information on how genetic variation might contribute to local adaptation. A locus which aligned to a predicted zona pellucida sperm-binding protein 3 gene (ZP3) in Atlantic cod was previously identified in Pacific cod populations as a high differentiation outlier. In other marine species, ZP3 is involved in reproductive isolation, local adaptation, and has neofunctionalized as an antifreeze gene, but the function of this genomic region is not understood in Pacific cod. We sequenced a 544 bp region of ZP3 in 230 Pacific cod collected from throughout their geographic range. Here we show that ZP3 haplotypes exhibit strong spatial structure and there is evidence for divergent selection at this locus in samples collected from the Bering Sea region. The potential for adaptation to different thermal regimes is particularly relevant given that Pacific cod have demonstrated high natural mortality during recent ocean warming events.
\end{abstract}

\section{Hosted file}

ZP3_manuscript10.pdf available at https://authorea.com/users/407541/articles/517825-evidencefor-divergent-selection-and-spatial-differentiation-in-a-putative-zona-pellucida-geneis-indicative-of-local-adaptation-in-pacific-cod 


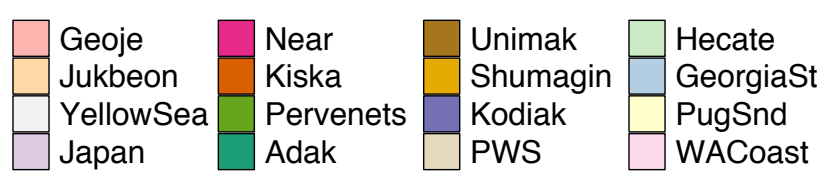

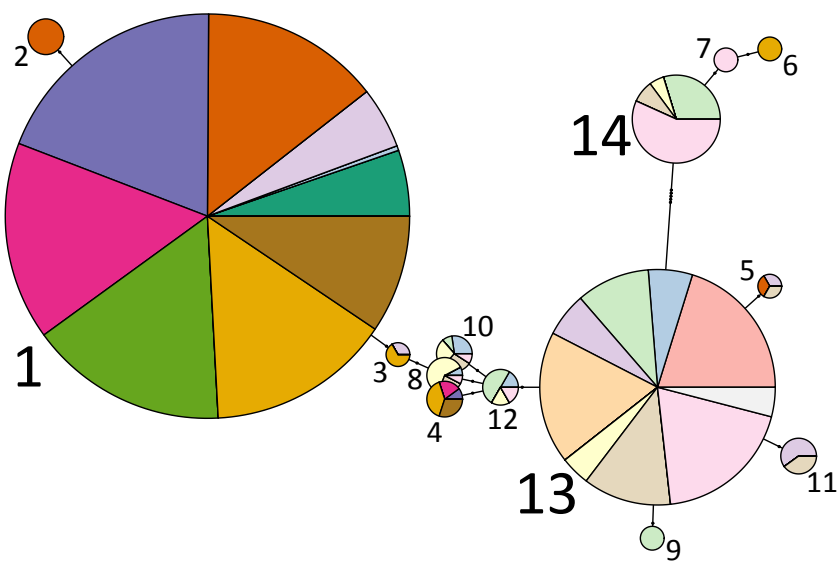

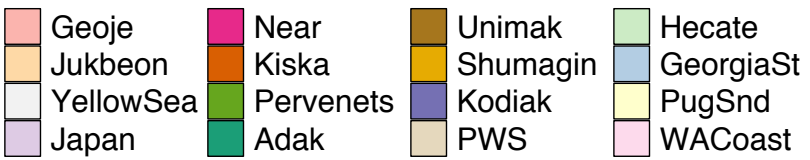

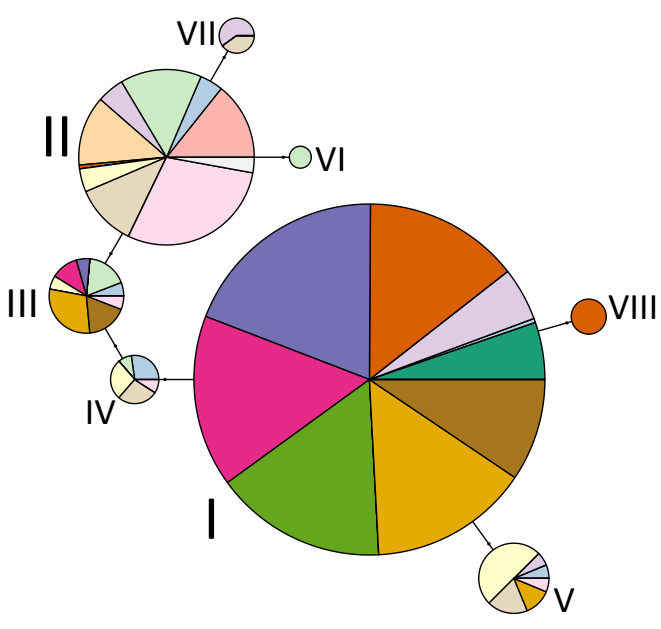




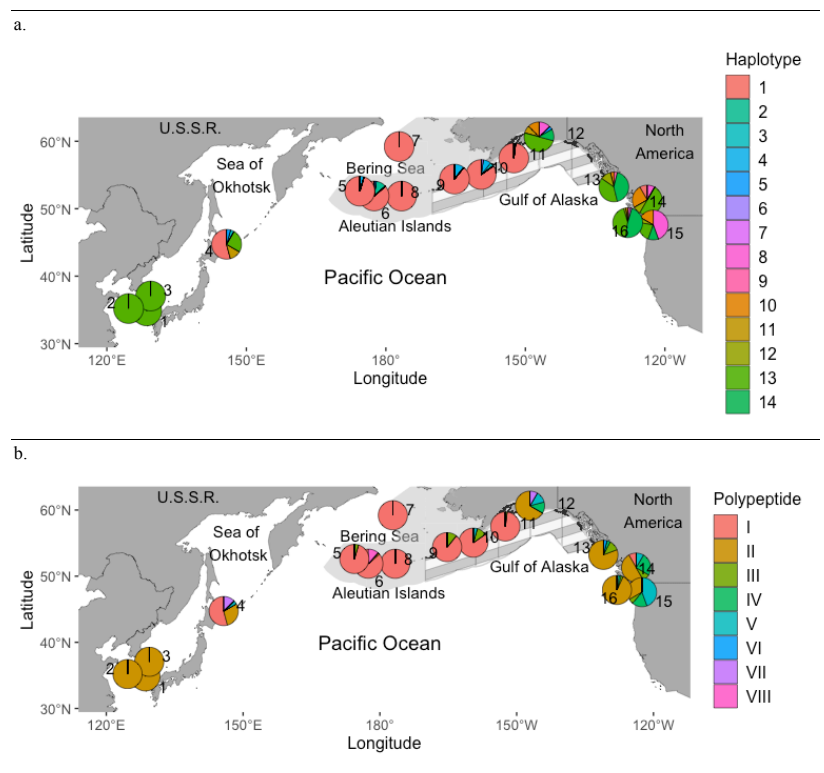




\section{Cluster dendrogram with p-values (\%)}

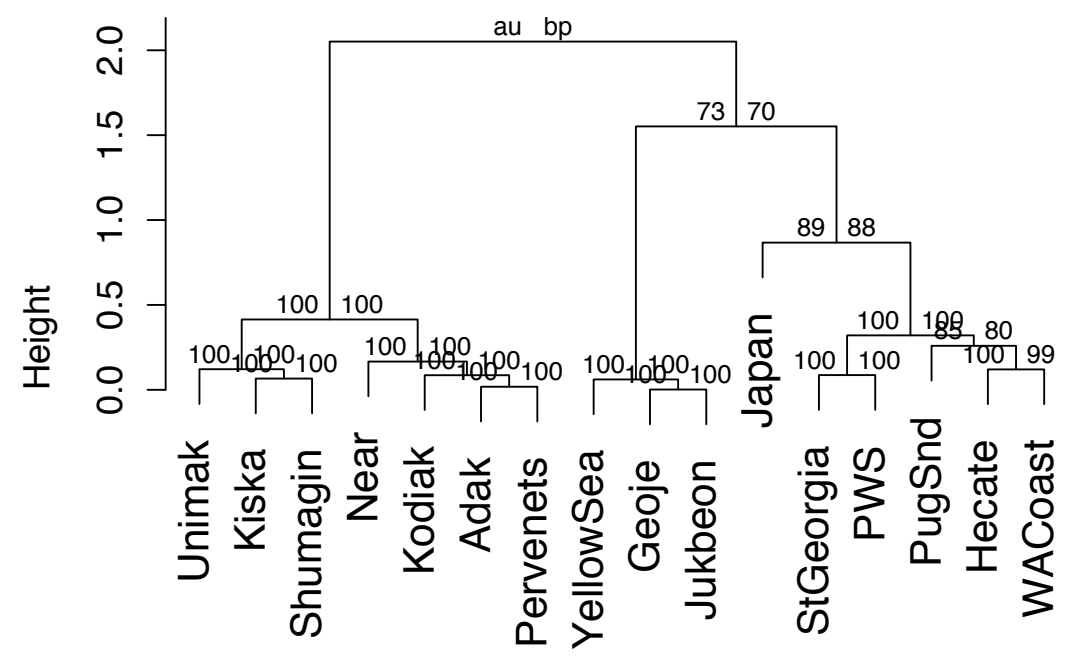

Distance: euclidean

Cluster method: average 